Erratum

\title{
A Novel Aurora-A Inhibitor, BPR IK0609SI, Sensitizes Colorectal Tumor cells to 5-Fluorofracil (5-FU) Treatment
}

Yoshimi Shionome 1, Wen-Hsing Lin 2, Hui-Yi Shiao ${ }^{2}$, Hsing-Pang Hsieh ${ }^{2}$, John Tsu-An Hsu ${ }^{2}$ and Toru Ouchi $1,3, \bowtie$

1. Department of Medicine, NUHS, Pritzker School of Medicine, The University of Chicago, Evanston, USA.

2. Institute of Biotechnology and Pharmaceutical Research National Health Research Institutes, Miaoli, Taiwan 305.

3. Department of Cancer Genetics, Roswell Park Cancer Institute, Buffalo, USA.

$\square$ Corresponding author: Toru Ouchi, Department of Cancer Genetics, Roswell Park Cancer Institute, Elm and Carlson Streets, Buffalo, NY 14263, USA. Phone: (716) 845-7173. Fax: (716) 845-1698 Email: Toru.Ouchi@RoswellPark.org.

() Ivyspring International Publisher. This is an open-access article distributed under the terms of the Creative Commons License (http://creativecommons.org/ licenses/by-nc-nd/3.0/). Reproduction is permitted for personal, noncommercial use, provided that the article is in whole, unmodified, and properly cited.

Published: 2013.09.22

Corrected article: Int J Biol Sci 2013; 9(4):403-4II.

In our above article of Int J Biol Sci 2013; 9(4): 403-411, we would like to clarify that control data using HCT116 and its derivative cells are shared with our PloS ONE paper [1]. Both papers are about the chemosensitivity of cells to several different Aurora-A inhibitors. We are sorry for the confusion.

\section{References}

1. Shionome Y, Yan L, Liu S, Saeki T, Ouchi T. Integrity of p53 Associated Pathways Determines Induction of Apoptosis of Tumor Cells Resistant to Aurora-A Kinase Inhibitors. PLoS ONE 2013;8(1): e55457. 